\title{
The Physicochemical Characteristic of Activated Carbon Based on Sludge and Preparation Method
}

\author{
H. Lu†, F. Luo, Q. Zhang, J. Li and L. Cai
}

School of Civil Engineering and Architecture, Wuhan Polytechnic University, Wuhan 430023, P.R. China

†Corresponding author: H. Lu; lhj_whpu@163.com

Nat. Env. \& Poll. Tech. Website: www.neptjournal.com

Received: $28-08-2020$

Revised: $19-10-2020$

Accepted: 08-12-2020

Key Words:

Sludge

Activated carbon

Adsorption

\begin{abstract}
To understand the features and best preparation of sludge activated carbon (SAC), and the pore structure, component, adsorption characteristics, and the yield rate of SAC, many tests have been carried out. The study illustrated that the pore structure was mostly mesopore and amorphous pore such as the ink bottle hole. In terms of different preparations to obtain SAC, the yield of SAC in sample No. 1 achieved $88.09 \%$. Using the preparation of $\mathrm{ZnCl}_{2}$ as an activator, the iodine adsorption value was significantly higher than other preparations. However, the content of quartz in sample No.1 achieved a maximum of $52.51 \%$. Charcoal was detected in all samples except sample nos $9-12$. The adsorption capacity of $\mathrm{Cu}(\mathrm{II})$ and $\mathrm{Cd}(\mathrm{II})$ reached a maximum of $600.02 \mathrm{mg} \cdot \mathrm{kg}^{-1}$ and $383.2 \mathrm{mg} \cdot \mathrm{kg}^{-1}$. The results showed an optimum preparation condition, which was by using the $\mathrm{ZnCl}_{2}$ as an activator, $2: 1$ as the impregnated ratio, $40 \%$ concentration in activator and at $400^{\circ} \mathrm{C}$ reaction temperature could create rich pore structure and charcoal inside.
\end{abstract}

\section{INTRODUCTION}

A number of problems in sewage treatment plants directly appear in real life such as continual increasing cost, sewage, sludge, and the low rate of resource utilization. According to government statistics, the amount of dry sludge produced when it is handled by municipal sewage bureaus in China is 15 million $t$ which accounts for $32 \%$ of total solid waste in China, and the annual growth rate is higher than $10 \%$ (Yang 2010). The contamination of water by heavy metal ions has become a big problem in China. To effectively prevent and improve this situation, many scientists are trying to find innovative methods like creating a strong and brand-new adsorption material to adsorb heavy metal ions instead of using traditional methods such as the chemical precipitation method and ion exchange. As we all know, activated carbon has the ability to remove heavy metal ions in water, which is a huge advantage. However, scientists indicate that the preparation of activated carbon is not easy, and the raw material cost is expensive especially if activated carbon is prepared using coal or wood as raw material. Hence, finding an alternate material is critical to resolving the cost problem (Lai et al. 2012). The inner composition of sludge contains high organic matters which can be used to generate activated carbon by using a rational method. Then the wasted sludge can be converted into a new material with adsorption properties. Wang et al. (2012) claimed that when the temperature in the pyrolysis test was set at $400-700^{\circ} \mathrm{C}$, with the thermal decomposition temperature enhancement, the decomposition fluid's production rate increased gradually. Li et al. (2012) found it was highly effective to prepare sludge activated carbon using $\mathrm{ZnCl}_{2}$ as an activator with rational concentration $(45 \%)$, and with the reaction temperature set at $\left(600^{\circ} \mathrm{C}\right)$, the immersed temperature set at $\left(45^{\circ} \mathrm{C}\right)$, and the reaction time being (50 mins). Moreover, he discovered that sludge activated carbon (SAC) had the adsorption ability to remove heavy metal ions as well. Li et al. (2013) found that when SAC is prepared from sewage sludge from a municipal sewage treatment plant combined with corn stalks, the results showed that when activated carbon was produced under the condition of $25 \%$ corn straw content and $500^{\circ} \mathrm{C}$ pyrolysis temperature, the BET surface area achieved $756 \mathrm{~m}^{2} \cdot \mathrm{g}^{-1}$. The yield presented a trend of gradually dropping with increasing temperature. When activated carbon was prepared under the temperature of $450^{\circ} \mathrm{C}$ and corn straw content of $25 \%$, yield attained the maximum value of $43.1 \%$.Liu and Liu (2013) stated that when the optimal combination was set at 3 mol. $\mathrm{L}^{-1}$ of $\mathrm{ZnCl}_{2}$, pyrolysis temperature was set at $550^{\circ} \mathrm{C}$, chemical activation was set for 2 hours and a liquid-solid ratio of $1.5: 1$, it showed that the adsorption of methylene blue in SAC was $41.9 \mathrm{mg}^{-\mathrm{g}^{-1}}$ with a yield of $48.9 \%$. Bao et al. (2012) revealed that the SAC surface with rich acidic functional groups played a crucial role in the adsorption of heavy metals, especially in terms of the adsorption of 
Cd(II). Neither the Langmuir nor Freundlich model described the isotherms satisfactorily, suggesting that the number of binding sites for $\mathrm{Cd}(\mathrm{II})$ on the surface of SAC was small. The adsorption of SAC was in ion exchange, and SAC could easily remove COD and TP from landfill leachate (Wu et al. 2017). SAC prepared by using $\mathrm{ZnCl} 2$ as an activator achieved good quality, the concentration of SAC was at 180 g.L $\mathrm{L}^{-1}$, and pollutants in wastewater decreased (Duan et al. 2016, Zheng et al. 2016). The product rate of SAC might be affected by temperature, time, and others, but the key influence is pyrolysis temperature (Agrafioti et al. 2013). The study illustrated that it was potential to use dewatering sludge as a modified agent for landfill liners, and the changes in the plastic index, hydraulic conductivity, and compressive strength were the main factors (Li et al. 2014).

In this paper, the rational preparation method, the inner pore structure, and the adsorption ability of SAC were performed. Several laboratory tests were conducted such as low-temperature nitrogen adsorption measurement, batch adsorption test, SEM, X-ray diffraction test, and the iodine adsorption value test. The low-temperature $\mathrm{N}_{2}$ adsorption test and the iodine adsorption value test were used to analyze pore structure, and the X-ray diffraction and SEM were used to examine the composition analysis. A batch adsorption test was used to understand the adsorption ability of $\mathrm{Cd}(\mathrm{II})$ and
$\mathrm{Cu}$ (II) to the SAC.

\section{MATERIALS AND METHODS}

\section{Test Materials}

The sludge was fresh from the Hanxi sewage treatment plant in Wuhan, Hubei Province, and the sludge used in the test was after the removal of water. The X-ray diffraction test was performed to obtain the elemental composition of sludge and the results are shown in Table 1. The determination method exhibited the physical characteristics of the sludge taken from the municipal sludge the wastewater treatment plant, which is shown in Table 2.

\section{Test Methods}

The recovered fresh sludge was dried in a drying oven at $105^{\circ} \mathrm{C}$. After the removal of all water, dried sludge was ground into powder in a ball grinding mill. The treated sludge was sieved through a $1 \mathrm{~mm}$ sieve, and then, the reaction condition was set for different impregnation ratios, different temperatures, and different activation concentrations. Finally, different activators were mixed with treated sludge till all the chemical reactions were completed. After 24 hours, a series of complex chemical reactions were performed. In the end, the SAC was sealed, after washing and drying it

Table 1: The elemental composition of sludge.

\begin{tabular}{|llllllllllll|}
\hline Element name & $\mathrm{C}$ & $\mathrm{O}$ & $\mathrm{Mg}$ & $\mathrm{Al}$ & $\mathrm{Si}$ & $\mathrm{P}$ & $\mathrm{S}$ & $\mathrm{K}$ & $\mathrm{Ca}$ & $\mathrm{Fe}$ & $\mathrm{Other}$ \\
\hline $\mathrm{m}(\%)$ & 7.87 & 54.1 & 1.28 & 5.80 & 14.83 & 2.34 & 1.87 & 1.54 & 3.77 & 5.19 & 1.41 \\
\hline
\end{tabular}

Table 2: The basic physical characteristics of sludge.

\begin{tabular}{|llllll|}
\hline $\mathrm{pH}$ & Specific gravity $(\mathrm{g} / \mathrm{mL})$ & Organic $(\%)$ & $\mathrm{W}(\%)$ & $\mathrm{e}$ & $\mathrm{K}(\mathrm{cm} / \mathrm{s})$ \\
\hline 6.96 & 1.24 & 43.2 & 80.3 & 3.36 & $1.20 \times 10^{-8}$ \\
\hline
\end{tabular}

Table 3: The orthogonality experiment.

\begin{tabular}{|c|c|c|c|c|}
\hline Affect & A & $\mathrm{B}$ & $\mathrm{C}$ & $\mathrm{D}$ \\
\hline Number & Activators & Temperature $\left({ }^{\circ} \mathrm{C}\right)$ & Impregnation Ratio & Concentration of Activator (\%) \\
\hline 1 & $\mathrm{ZnCl}_{2}$ & 400 & $2: 1$ & 40 \\
\hline 2 & $\mathrm{ZnCl}_{2}$ & 500 & $1: 1$ & 45 \\
\hline 3 & $\mathrm{ZnCl}_{2}$ & 600 & $1: 2$ & 50 \\
\hline 4 & $\mathrm{ZnCl}_{2}$ & 700 & $1: 3$ & 55 \\
\hline 5 & $\mathrm{H}_{3} \mathrm{PO}_{4}$ & 400 & $1: 1$ & 55 \\
\hline 6 & $\mathrm{H}_{3} \mathrm{PO}_{4}$ & 500 & $2: 1$ & 50 \\
\hline 7 & $\mathrm{H}_{3} \mathrm{PO}_{4}$ & 600 & $1: 3$ & 45 \\
\hline 8 & $\mathrm{H}_{3} \mathrm{PO}_{4}$ & 700 & $1: 2$ & 40 \\
\hline 9 & $\mathrm{Na}_{2} \mathrm{CO}_{3}$ & 400 & $1: 3$ & 50 \\
\hline 10 & $\mathrm{Na}_{2} \mathrm{CO}_{3}$ & 500 & $1: 2$ & 55 \\
\hline 11 & $\mathrm{Na}_{2} \mathrm{CO}_{3}$ & 600 & $1: 1$ & 40 \\
\hline 12 & $\mathrm{Na}_{2} \mathrm{CO}_{3}$ & 700 & $2: 1$ & 45 \\
\hline
\end{tabular}


again. According to the preparation conduction, as shown in Table 3, a series of tests was conducted.

To check the yield of SAC obtained from different preparations, the formula is as below:

$$
P=\frac{m_{a}}{m_{c}} \times 100 \%
$$

Where $P$ is the yield of activated charcoal, $m_{a}$ is the weight of the sample after carbonizing, $m_{c}$ is the weight of the sample before carbonizing.

Iodine adsorption value test: According to the test method of wooden activated carbon-determination of iodine number (GB/T12496.8-1999), $10 \mathrm{~mL}$ of hydrochloric acid solution with $0.50 \mathrm{~g} \mathrm{SAC}$ was added into a conical bottle, and the bottle was shaken to fully moist the solution in the bottle. Then, it was heated, boiling for 30 seconds. After the temperature cooled down, $50.0 \mathrm{~mL}$ of iodine standard solution was added into the conical bottle, after that the bottle was sealed. The bottle vibrated in an oscillator for 15 mins and was filtered quickly. The $10 \mathrm{~mL}$ solution extracted from the conical bottle was mixed with $100 \mathrm{~mL}$ distilled water, and finally, it was titrated with the standard solution of sodium thiosulfate. The iodine adsorption value was calculated by the following formula:

$$
\mathrm{A}=\frac{5\left(10 \mathrm{C}_{1}-1.2 \mathrm{C}_{2} \mathrm{~V}_{2}\right) \times 126.93}{m}
$$

Where $A$ is the iodine adsorption value, $C_{1}$ is the concentration of the standard solution of iodine, $C_{2}$ is the concentration of the standard solution of sodium thiosulfate, $V$ is the volume of sodium thiosulfate, $c$ is the concentration of the rest of the filtrate solution and $m$ is the weight of the SAC.

\section{Low-temperature nitrogen adsorption measurement:} Using the JW-BK static nitrogen adsorption instrument, the pore structure characteristics of SAC were examined. $0.50 \mathrm{~g}$ of SAC was dipped in $99.99 \%$ liquid nitrogen, then the reaction was observed and the results were obtained. The JW-BK static nitrogen adsorption instrument uses different values of $\mathrm{P} / \mathrm{P}_{0}$ to predict the pore distribution. In the end, the specific surface area, pore size, and pore volume distribution of SAC were calculated according to the standard BET method.

$X$-ray diffraction test and SEM test: The samples used in the XRD test were samples after different chemical activation preparation methods. The XRD test was repeated about four times with SAC which was obtained from different chemical activation preparation methods. The composition of the samples was determined by using $\mathrm{X}$-ray diffraction (Holland PA Nalytical Co.Ltd) with a $\mathrm{Cu}-\mathrm{K} \alpha$ operating at $45 \mathrm{kV}$ and 40 $\mathrm{mA}$. The divergence slit was $0.19 \mathrm{~mm}$. The scanning speed was $6^{\circ} \cdot \min ^{-1}(2 \theta)$. Data were recorded between $5^{\circ}$ and $85^{\circ}$ with a step size of $0.04^{\circ}$.
The microstructure of the SAC was observed by using an S-3000 N scanning electron microscope. To obtain detailed data of SAC, the samples of SAC were selected carefully, and the SEM test was carried out in three groups of parallel tests with the same sample. The samples were air-dried and stored at $5^{\circ} \mathrm{C}$. However, the surface of SAC was gilt with a thickness of approximately $20 \mathrm{~nm}$ according to the "General rules for analytical scanning electron microscopy" (JY/T 010-1996). Surface micromorphology was tested by using an S-3000N scanning electron microscope (Hitachi, Japan). SEM images with magnifications of $1000 \times$ were obtained.

Batch adsorption test: The $3 \mathrm{~g}$ sample in the test, which was obtained from three different preparation methods, was numbered 1,5, and 9, respectively, and then immersed in $25 \mathrm{~mL}$ $\mathrm{Cd}$ (II) or $\mathrm{Cu}$ (II) chemical solutions. The initial concentration of $\mathrm{Cd}(\mathrm{II})$ or $\mathrm{Cu}$ (II) was 50-350 mg. $\mathrm{L}^{-1}$. After mixing evenly, the mixture was placed in a water bath instrument at $25^{\circ} \mathrm{C}$. Then, the mixed solution was quiesced for 24 hours, and the concentration of $\mathrm{Cd}(\mathrm{II})$ or $\mathrm{Cu}(\mathrm{II})$ in the suspension solution after centrifugation was measured by spectrophotometry (Shanghai Third Analytical Instruments Factory) according to GB 7467-87 DPC. The concentration of heavy metal ions adsorbed on the SAC was calculated from the mass balance:

$$
q_{e}=\frac{\left(C_{0}-C_{e}\right) \cdot V}{M} \times 100 \%
$$

Where $q_{e}$ is the adsorbed amount of $\mathrm{Cd}$ (II) or $\mathrm{Cu}$ (II) onto SAC, $C_{0}$ is the initial concentration of $\mathrm{Cd}(\mathrm{II})$ or $\mathrm{Cu}(\mathrm{II}), C_{e}$ is the equilibrium concentration of $\mathrm{Cd}(\mathrm{II})$ or $\mathrm{Cu}(\mathrm{II}), V$ is the volume of the aqueous phase and $M$ is the weight of the SAC.

\section{RESULTS AND DISCUSSION}

\section{Iodine Adsorption Value Test}

As depicted in Fig. 1, it was revealed that different preparation methods affected the overall yield of SAC, and the range of yield was between $62.01 \%$ to $88.09 \%$. When the activator was $\mathrm{ZnCl}_{2}, \mathrm{H}_{3} \mathrm{PO}_{4}, \mathrm{Na}_{2} \mathrm{CO}_{3}$, the highest yield of $\mathrm{SAC}$ was $88.09 \%, 83.98 \%$, and $79.63 \%$, respectively. It was obvious that the yield of SAC was more than $80 \%$ when $\mathrm{ZnCl}_{2}$ was chosen as the activator, and the least yield of SAC, which was less than $80 \%$, was when $\mathrm{Na}_{2} \mathrm{CO}_{3}$ was chosen as the activator. Thus, the best order of acquisition rate of SAC was $\mathrm{ZnCl}_{2}>\mathrm{H}_{3} \mathrm{PO}_{4}>\mathrm{Na}_{2} \mathrm{CO}_{3}$. The results claimed that by selecting $\mathrm{ZnCl}_{2}$ as an activator, the maximum yield of $\mathrm{SAC}$ could be achieved. Even if the rest of the conditions were different, except activators, the SAC prepared by $\mathrm{ZnCl}_{2}$ achieved a high yield compared to the others.

Fig. 2 shows SAC produced by different preparation methods presented by the difference in the degree of pores, directly causing the value of iodine adsorption capacity. 


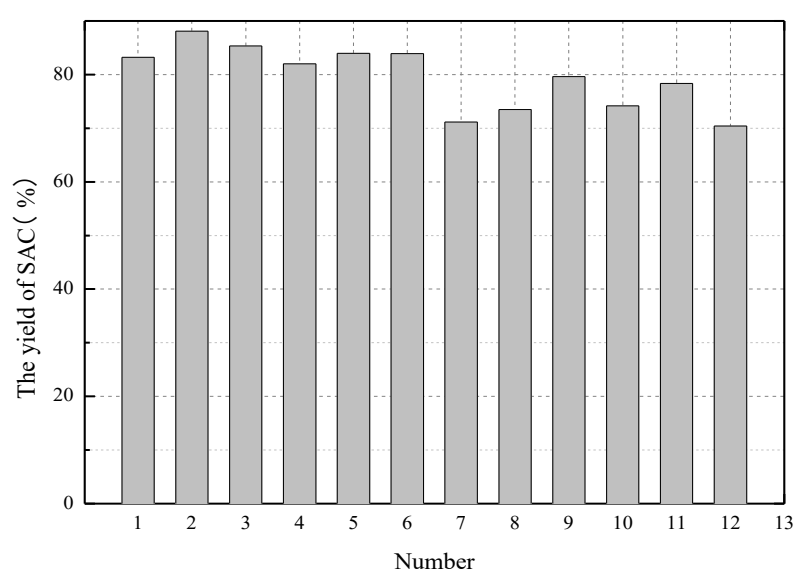

Fig. 1: The yield of SAC.

As shown in Fig. 2(a), with the increase of activation temperature, by selecting $\mathrm{ZnCl}_{2}$ and $\mathrm{H}_{3} \mathrm{PO}_{4}$ as the activators to prepare $\mathrm{SAC}$, the curves showed a downward trend as a whole. When the activation temperature was at $400^{\circ} \mathrm{C}$, taking $\mathrm{ZnCl}_{2}, \mathrm{H}_{3} \mathrm{PO}_{4}$, and $\mathrm{Na}_{2} \mathrm{CO}_{3}$ as the activators, the maximum value of iodine adsorption capacity was achieved, and the iodine adsorption value was 452.16, 363.69, $257.80 \mathrm{mg} \mathrm{g}^{-1}$, respectively. Fig. 2(b) showed the value of iodine adsorption in the sample was variable with the change of impregnated ratio under different preparation methods. By choosing $\mathrm{H}_{3} \mathrm{PO}_{4}$ as an activator to produce $\mathrm{SAC}$, the impregnated ratio was 1: 1 , the iodine adsorption value in the sample reached a maximum of $363.69 \mathrm{mg} \cdot \mathrm{g}^{-1}$, and the iodine adsorption value corresponding to the impregnated ratio was in the range of 240.37 to $273.88 \mathrm{mg} \cdot \mathrm{g}^{-1}$. However, when using $\mathrm{Na}_{2} \mathrm{CO}_{3}$, as an activator, the curve is stable and the iodine adsorption value in the sample was in the range of 221.61 to 263.16 $\mathrm{mg} \cdot \mathrm{g}^{-1}$. According to Fig. 2(c), with the increase of the concentration in the activator, it was evident that there was a change in the curves once the activator chosen was either $\mathrm{ZnCl}_{2}$ or $\mathrm{H}_{3} \mathrm{PO}_{4}$. Moreover, when using $\mathrm{ZnCl}_{2}$ as an activator to prepare SAC, and the concentration is at $40 \%$, the value of iodine adsorption was the maximum at $452.16 \mathrm{mg}^{-1}{ }^{-1}$. However, the concentration of $\mathrm{H}_{3} \mathrm{PO}_{4}$ at $50 \%$ to prepare SAC resulted in a maximum iodine adsorption value of 363.69 $\mathrm{mg} / \mathrm{g}^{-1}$. Hence, as shown in Fig. 2, the curves of $\mathrm{ZnCl}_{2}$ as an activator were all distributed at the top of other curves which depicted other activators, and the iodine adsorption value in the sample was obviously higher than that of the others. Moreover, the development of micropores (>1.0 nm) was better than the others as well. By contrast experiments, for the preparation of SAC, the best option was $\mathrm{ZnCl}_{2}$ as an activator, the impregnated ratio at $2: 1$, the concentration in activator at $40 \%$, and the reaction temperature at $400^{\circ} \mathrm{C}$.

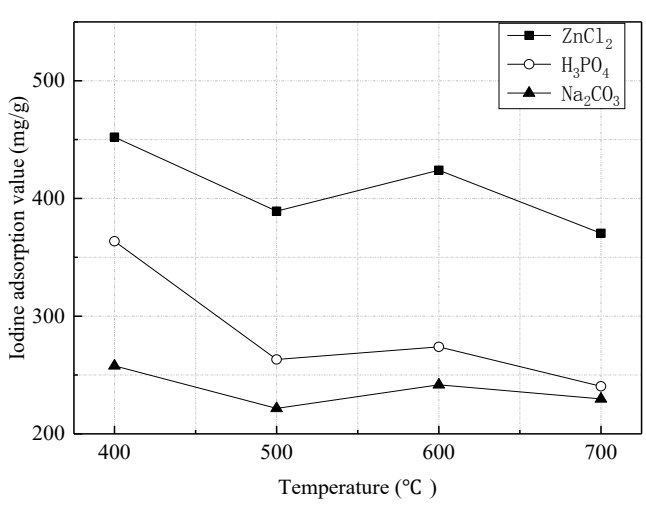

(a)

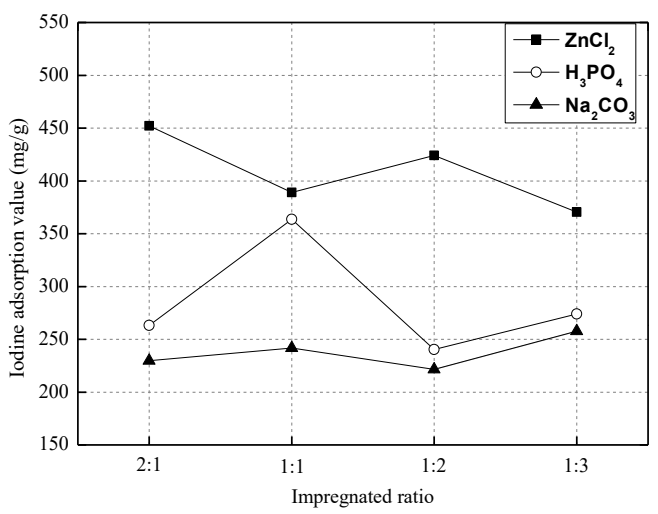

(b)

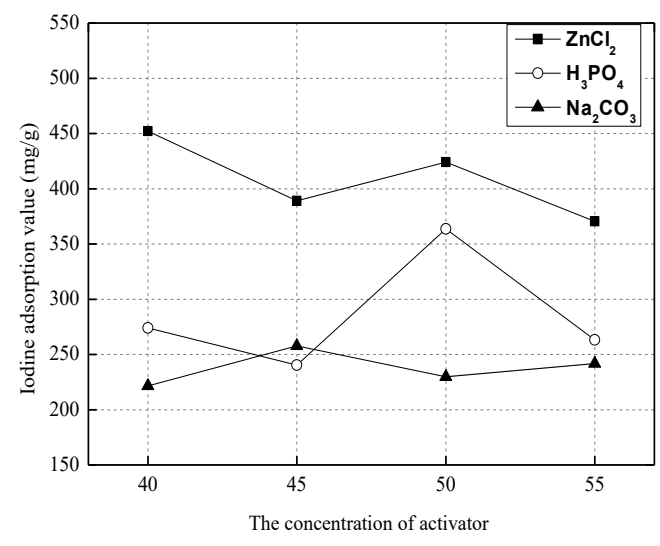

(C)

Fig. 2: The value of the iodine adsorption curve.

\section{Low-Temperature Nitrogen Adsorption Measurement}

According to Fig. 3, it was revealed that the adsorptiondesorption isotherm curves and the tendency were similar 
even if the SAC was prepared under different conditions. Selecting $\mathrm{ZnCl}_{2}$ as an activator, the temperature at $400^{\circ} \mathrm{C}$, the impregnated ratio at 2:,1 and the concentration of activator at $40 \%$ to analyze, $\mathrm{N}_{2}$ absorbed to $\mathrm{SAC}$ varied with variation in relative pressure $\left(\mathrm{P} / \mathrm{P}_{0}\right)$. When the relative pressure was low, the main adsorption method was single-molecule adsorption and the speed of adsorption was slow, however, the trend of the curve was more stable. When the relative pressure $(\mathrm{P} /$ $\mathrm{P}_{0}$ ) was close to $0.4, \mathrm{~N}_{2}$ was forced to enter the pores. Due to the action of capillary condensation, the gas state of $\mathrm{N}_{2}$ was converted into liquid nitrogen, thus the surface of SAC was accumulated with nitrogen, and the isotherm curve continued moving upward. The liquid nitrogen was adsorbed to the pores of SAC until the relative pressure approximately reached 1 . In terms of IUPAC classification, the isotherm was the IV category. There was an $\mathrm{H} 2$ hysteresis loop in the process of adsorption and desorption. Moreover, the hyster-

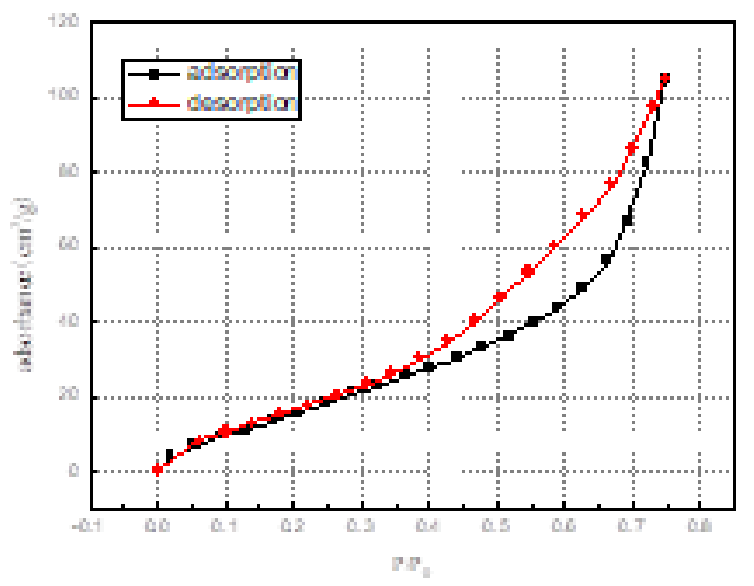

Fig. 3: Sorption isotherm of SAC.

Table 4: The microstructure parameters of SAC.

\begin{tabular}{|llll|}
\hline Number & $\begin{array}{l}\text { Total pore volume } \\
\left(\mathrm{cm}^{3} \cdot \mathrm{g}-1\right)\end{array}$ & $\mathrm{D}(\mathrm{nm})$ & $\begin{array}{l}\text { Specific surface } \\
\text { area }\left(\mathrm{m}^{2} \cdot \mathrm{g}^{-1}\right)\end{array}$ \\
\hline 1 & 0.1017 & 5.67 & 537.22 \\
2 & 0.1028 & 8.05 & 457.84 \\
3 & 0.0910 & 7.96 & 493.99 \\
4 & 0.1232 & 7.63 & 427.37 \\
5 & 0.0879 & 5.33 & 415.65 \\
6 & 0.0925 & 5.71 & 297.92 \\
7 & 0.0752 & 5.39 & 307.16 \\
8 & 0.0797 & 5.48 & 267.08 \\
9 & 0.1304 & 8.24 & 294.63 \\
10 & 0.1318 & 7.63 & 250.88 \\
11 & 0.0926 & 7.94 & 271.09 \\
12 & 0.0220 & 7.31 & 255.17 \\
\hline
\end{tabular}

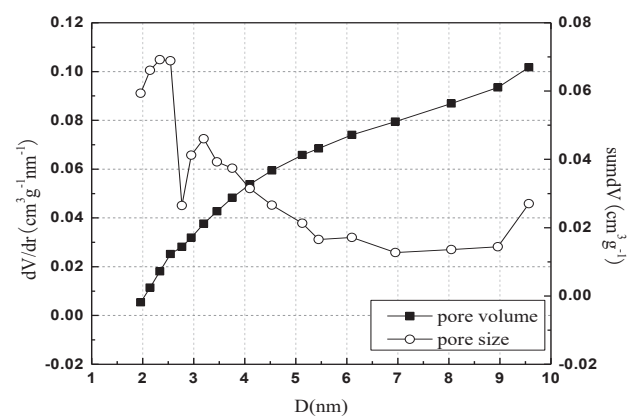

(a)

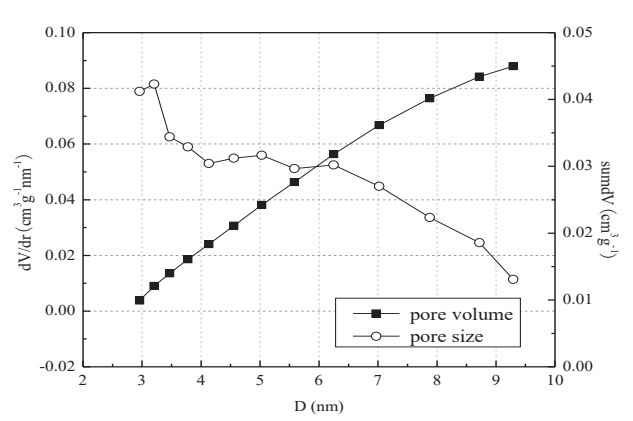

(b)

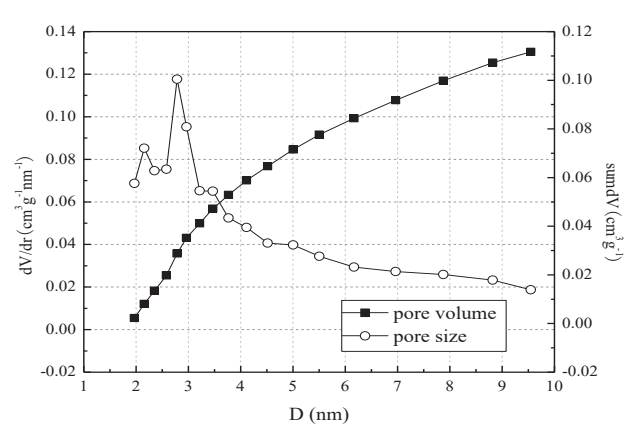

(c)

Fig. 4: The pore volume and pore size distributions of SAC (a) $\mathrm{ZnCl}_{2}$ (b) $\mathrm{H}_{3} \mathrm{PO}_{4}$ (c) $\mathrm{Na}_{2} \mathrm{CO}_{3}$.

etic curve reflected the pore kind was amorphous pores such as the ink bottle hole. The reasons were as follows: With abundant pores in SAC, there was enough room for nitrogen to enter. The nitrogen inside was not allowed to come out because of the changing pressure or the pores in SAC which easily blocked nitrogen into the orifice.

Fig. 4 showed the analysis of the pore size and pore volume under the different preparation methods. Due to the high similarity of samples from the same activator, three SAC samples with the largest specific surface area, prepared 
by using $\mathrm{ZnCl}_{2}, \mathrm{H}_{3} \mathrm{PO}_{4}$, and $\mathrm{Na}_{2} \mathrm{CO}_{3}$, were selected for the analysis, which were numbered No. 1, No. 5, and No. 9, respectively. Fig. 4(a) shows that sample No. 1 had a peak value of $2.34 \mathrm{~nm}$ and $3.19 \mathrm{~nm}$; the peak value of sample No. 5 was $3.21 \mathrm{~nm}$ as shown in Fig. 4(b). Moreover, the peak value of sample No.9 was $2.8 \mathrm{~nm}$ and $2.78 \mathrm{~nm}$ as shown in Fig. 4(c). The microstructure parameters such as total pore volume, average pore size, and specific surface area of SAC are shown in Table 4. The total pore volume of the sample was between 0.0220 to $0.1318 \mathrm{~cm}^{3} \cdot \mathrm{g}^{-1}$, and the average pore size was between 5.33 to $11.60 \mathrm{~nm}$, however, the specific surface area was distributed in the range of 250.88 to 537.22 $\mathrm{m}^{2} \cdot \mathrm{g}^{-1}$. According to the IUPAC classification, the pore size distribution of 2-50 $\mathrm{nm}$ is called mesoporous. Since the pore size distribution was in the range of $2-10 \mathrm{~nm}$, as shown in the results, the pore in SAC was mainly mesoporous. The above results could be explained as follows: It was obvious that the preparation method using $\mathrm{ZnCl}_{2}$ as an activator was beneficial for the development of pore structure and specific surface area. Moreover, the skeleton in the process of carbonation forced newly formed charcoal to attach to it. During the conditions of pyrolysis, catalysis, and dehydration, at high temperatures, it produced a rich pore structure inside the sludge (Yuan \& Liu 2015). It was indirectly observed that the adsorption capacity was the highest because SAC provided lots of contact areas in its abundant specific surface area.

\section{X-ray Diffraction Test}

Fig. 5 showed the X-ray diffraction pattern in SAC with different preparation methods. The main mineral composition of SAC is seen in Table 5. Thus, the data proved that the compositions of SAC were different under different pyrolysis with different activators. The quartz composition in the samples was stable and more than $50 \%$, however, the quartz contents of samples 9-12, which was in the range of $53.45 \%$ to $54.01 \%$, was high compared to others. Charcoal in samples 1-8 shows that it was feasible to prepare carbon-containing material by compatible processing. Among those samples, the content of charcoal was pretty high, and when the preparation method was by using $\mathrm{ZnCl}_{2}$, the maximum percentage of charcoal was $52.51 \%$. At the same time, charcoal was not detected in samples 9-12. Moreover, quartz was the main peak in all samples. Furthermore, the main components of SAC prepared by $\mathrm{ZnCl}_{2}$ or $\mathrm{H}_{3} \mathrm{PO}_{4}$ were similar, including quartz $\left(26.70^{\circ}, 50.2^{\circ}\right)$, charcoal $\left(22.00^{\circ}\right.$, $\left.42.00^{\circ}\right)$, muscovite $\left(19.90^{\circ}, 35.00^{\circ}\right)$, and berlinite $\left(21.00^{\circ}\right.$, $26.60^{\circ}$ ). However, SAC had an obvious diffraction peak at $22.00^{\circ}$ and $42.00^{\circ}$. The diffraction peak $\left(2 \theta=22^{\circ}\right)$ was the crystal plane of microcrystal (002) in graphite-like structure, and the diffraction peak $\left(2 \theta=42^{\circ}\right)$ was the crystal plane of microcrystal (100) with graphite-like structure. The reasons

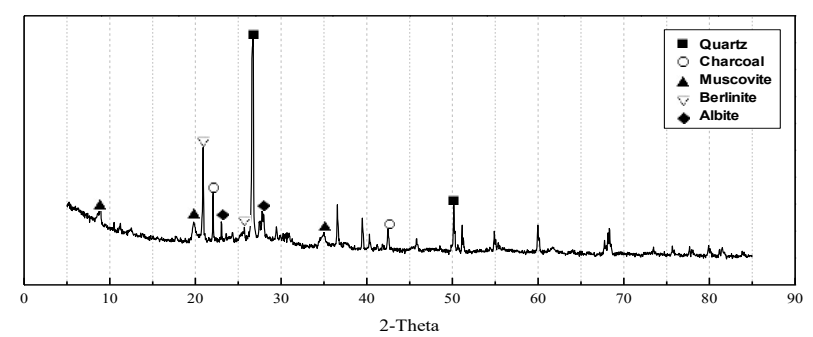

(a)

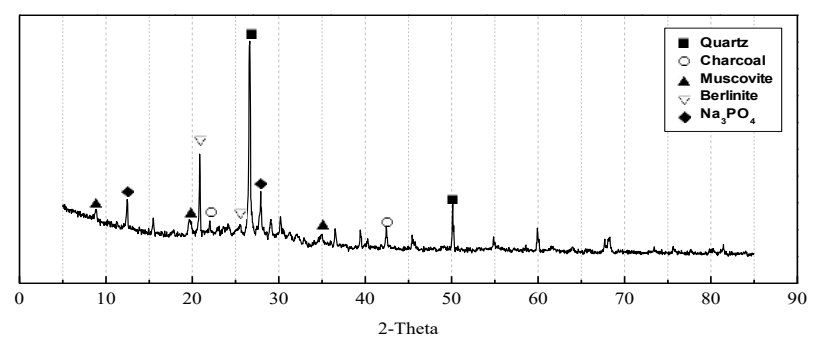

(b)

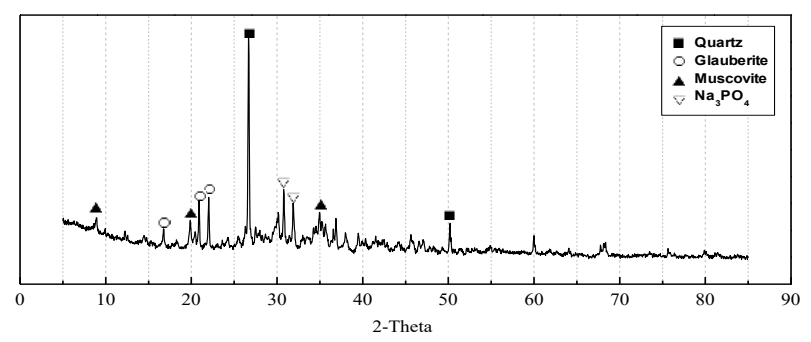

(c)

Fig. 5: The X-ray diffraction pattern (a) $\mathrm{ZnCl}_{2}$ (b) $\mathrm{H}_{3} \mathrm{PO}_{4}$ (c) $\mathrm{Na}_{2} \mathrm{CO}_{3}$.

were as follows: Because $\mathrm{ZnCl}_{2}$ had little effect on the cellulose in SAC, more and more celluloses were crystallized into graphite. Moreover, the diffraction peak of microcrystalline graphite was enhanced. Furthermore, the higher the degree of crystallization, the more stable carbon compounds were formed. It was proved that this preparation method was the best option to prepare SAC because of the evidence of abundant pore structure, the high content of charcoal and stable substances.

As shown in Fig. 6(a), the magnification of samples was 1000 times. It could be seen that the structure of sample No. 1 was a honeycomb structure, and the surface of the sample was rough with a porous carbon skeleton structure inside. Moreover, the particle unit body was mainly composed of flake, and the structure of sample No. 1 was characterized by simple stacking, mostly edge-surface contact and edge-edge contact with a large number of pores and rich pore structure. 
Table 5: The mineral composition of SAC.

\begin{tabular}{|c|c|c|c|c|c|c|c|}
\hline Activator & Number & Quartz & Charcoal & Muscovite & Berlinite & Albite & Others \\
\hline \multirow[t]{4}{*}{$\mathrm{ZnCl}_{2}$} & 1 & $52.45 \%$ & $3.84 \%$ & $31.71 \%$ & $3.82 \%$ & $6.57 \%$ & $1.61 \%$ \\
\hline & 2 & $52.43 \%$ & $4.12 \%$ & $32.47 \%$ & $4.15 \%$ & $5.03 \%$ & $1.80 \%$ \\
\hline & 3 & $52.51 \%$ & $4.06 \%$ & $32.92 \%$ & $4.28 \%$ & $4.94 \%$ & $1.29 \%$ \\
\hline & 4 & $52.35 \%$ & $3.97 \%$ & $31.28 \%$ & $3.35 \%$ & $7.57 \%$ & $1.48 \%$ \\
\hline Activator & Number & Quartz & Charcoal & Muscovite & Berlinite & $\mathrm{Na}_{3} \mathrm{PO}_{4}$ & Others \\
\hline \multirow[t]{4}{*}{$\mathrm{H}_{3} \mathrm{PO}_{4}$} & 5 & $52.93 \%$ & $2.94 \%$ & $31.79 \%$ & $6.14 \%$ & $4.71 \%$ & $1.49 \%$ \\
\hline & 6 & $53.11 \%$ & $2.52 \%$ & $33.64 \%$ & $5.46 \%$ & $3.91 \%$ & $1.36 \%$ \\
\hline & 7 & $52.91 \%$ & $2.89 \%$ & $34.07 \%$ & $6.03 \%$ & $2.85 \%$ & $1.25 \%$ \\
\hline & 8 & $52.89 \%$ & $2.31 \%$ & $33.27 \%$ & $5.90 \%$ & $3.67 \%$ & $1.96 \%$ \\
\hline Activator & Number & Quartz & Charcoal & Muscovite & $\mathrm{Na}_{3} \mathrm{PO}_{4}$ & Glauberite & Others \\
\hline \multirow[t]{4}{*}{$\mathrm{Na}_{2} \mathrm{CO}_{3}$} & 9 & $53.56 \%$ & - & $32.82 \%$ & $5.66 \%$ & $6.59 \%$ & $1.37 \%$ \\
\hline & 10 & $54.01 \%$ & - & $33.37 \%$ & $7.34 \%$ & $3.50 \%$ & $1.78 \%$ \\
\hline & 11 & $53.62 \%$ & - & $32.67 \%$ & $5.25 \%$ & $6.92 \%$ & $1.54 \%$ \\
\hline & 12 & $53.45 \%$ & - & $34.23 \%$ & $6.73 \%$ & $4.34 \%$ & $1.25 \%$ \\
\hline
\end{tabular}

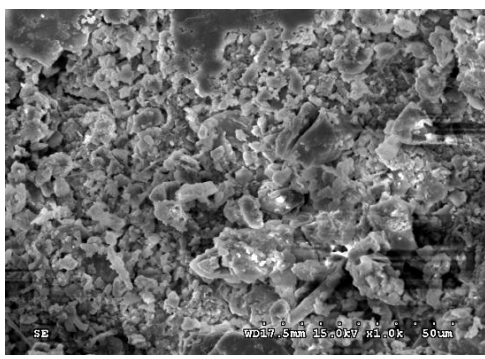

(a)

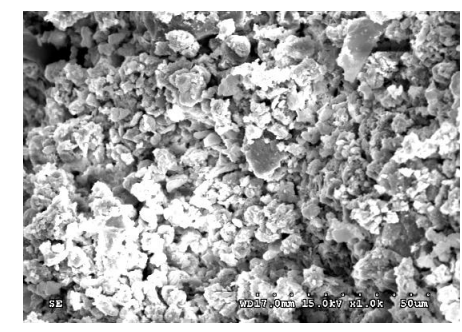

(b)

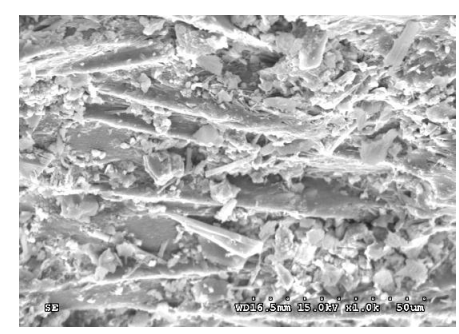

(c)

Fig. 6: SEM Images (magnified 1000 times) of $\mathrm{SAC}$ (a) $\mathrm{ZnCl}_{2}$ (b) $\mathrm{H}_{3} \mathrm{PO}_{4}$ (c) $\mathrm{Na}_{2} \mathrm{CO}_{3}$.
As shown in Fig. 6(b), sample No. 5 was mainly composed of aggregated granular structure, and the pore structure was not more obvious than sample No.1. As shown in Fig. 6(c), the structure of sample No. 9 was a flake structure that was mainly surface-to-surface contact. Moreover, the surface of the sample had folds with rich irregular strip debris on the surface. The results of the iodine adsorption value test and low-temperature nitrogen adsorption test show that sample No. 1 had a large number of pores, rich pore structures, and specific surface areas compared to other samples, therefore, the activation of $\mathrm{ZnCl}_{2}$ had a positive effect on the pore structure of SAC.

\section{Batch Adsorption Test}

The adsorption isotherm for $\mathrm{Cu}(\mathrm{II})$ and $\mathrm{Cd}(\mathrm{II})$ under different preparation methods are shown in Fig 7. With the different preparation methods, the adsorption capacity of $\mathrm{Cu}(\mathrm{II})$ increased dramatically. Moreover, the adsorption capacity reached the highest value at $600.02 \mathrm{mg} \cdot \mathrm{kg}^{-1}$ when SAC was prepared using $\mathrm{ZnCl}_{2}$ as an activator, and the least value was $412.17 \mathrm{mg} . \mathrm{kg}^{-1}$ when $\mathrm{Na}_{2} \mathrm{CO}_{3}$ was used as an activator. In the preparation method using $\mathrm{H}_{3} \mathrm{PO}_{4}$ as an activator, the adsorption capacity had a mid-value (between the highest and least) and the value of adsorption was $512.97 \mathrm{mg} \cdot \mathrm{kg}^{-1}$. When the curves of adsorption capacity of Cd(II) was highly similar to $\mathrm{Cu}(\mathrm{II})$, the highest adsorption value was 383.2 mg. $\mathrm{kg}^{-1}$, and the minimum value for the adsorption capacity was $227.75 \mathrm{mg} \cdot \mathrm{kg}^{-1}$, and the highest adsorption capacity was $315.25 \mathrm{mg} \cdot \mathrm{kg}^{-1}$ when $\mathrm{H}_{3} \mathrm{PO}_{4}$ was the activator. In the last phase, the adsorption did not take place because of the phenomenon of Coulomb repulsion. The values of the isotherm 


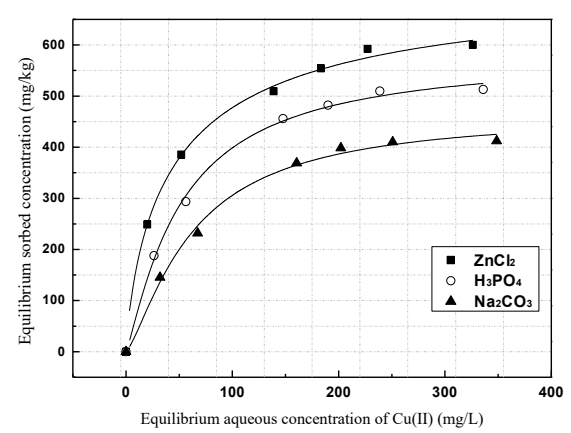

(a)

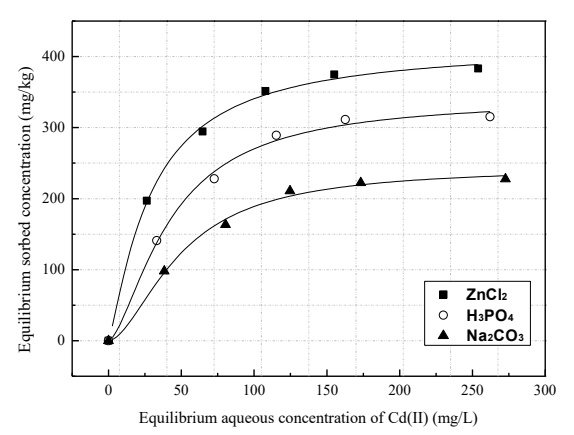

Fig. 7: The adsorption isotherm with different preparation methods (a) $\mathrm{Cu}$ (II) (b) $\mathrm{Cd}(\mathrm{II})$.

parameters are given in Table 6. All adsorptions belonged to the Langmuir isotherm model, especially the adsorption of $\mathrm{Cu}$ (II). Moreover, the high accuracy of the model and the $\mathrm{R}^{2}$ which almost reached 1 was the best evidence to prove that SAC had loose structure, large porosity, and specific surface area, however, SAC has the potential and feasibility to adsorb all polluted matters regardless of the method used to prepared SAC. In terms of the various preparation methods, to get SAC, sample No.1, which was the preparation method using $\mathrm{ZnCl}_{2}$, provided more pores for the heavy metals. However, using others preparation were also rational choices expect the number of pores was not enough when compared to sample No. 1 .

\section{CONCLUSION}

To explore the physicochemical characteristics and the optimum preparation condition of SAC, a series of tests were conducted, such as low-temperature nitrogen adsorption measurement, XRD, SEM, batch adsorption test, and the iodine adsorption value test. To analyze the yield of SAC the iodine adsorption value test was performed. The adsorption capacity of $\mathrm{Cu}(\mathrm{II})$ and $\mathrm{Cd}(\mathrm{II})$ to SAC was observed by performing the batch adsorption test. The pore structure, pore volume, and components of the SAC were observed by performing the low-temperature $\mathrm{N}_{2}$ adsorption test, $\mathrm{XRD}$, and SEM. The following conclusions can be drawn:

1. The order of yield rate of SAC prepared by different activators is $\mathrm{ZnCl}_{2}>\mathrm{H}_{3} \mathrm{PO}_{4}>\mathrm{Na}_{2} \mathrm{CO}_{3}$. When $\mathrm{ZnCl}_{2}$ is selected as the activator for the preparation of $\mathrm{SAC}$, the iodine adsorption value is significantly higher than that of other activators, and the micropores $(>1.0 \mathrm{~nm})$ in the obtained SAC are highly developed.

2. In accordance with the IUPAC classification method, the SAC isotherms belong to the IV category, and the hysteretic curve is $\mathrm{H} 2$ kind, moreover, the pore of SAC is mostly mesopore.

3. The quartz composition in all samples is more than $50 \%$, and charcoal was observed in sample Nos 1-8 but not in sample Nos 9-12. The content of charcoal was maximum at $52.51 \%$ when the preparation method of $\mathrm{SAC}$ is with $\mathrm{ZnCl}_{2}$ as an activator.

4. The results showed an optimum preparation condition - which was by using the $\mathrm{ZnCl}_{2}$ as an activator, 2:1 as the impregnated ratio, $40 \%$ concentration in activator and at $400^{\circ} \mathrm{C}$ reaction temperature - could create rich pore structure and charcoal inside. .

\section{ACKNOWLEDGEMENTS}

The authors would like to express their great appreciation for funding provided by the "National Natural Science Foundation of China (U20A20320)".

\section{REFERENCES}

Agrafioti, E., Bouras, G., Kalderis, D. and Diamadopoulos, E. 2013. Biochar production by sewage sludge pyrolysis. J. Anal. Appl. Pyrol., 101(5): 72-78.

Bao, H. F., Yang, W. W., Zhang, L. Q. and Feng, L. 2012. Efficiency and

Table 6: The isotherm parameter for $\mathrm{Cd}(\mathrm{II})$ and $\mathrm{Cu}(\mathrm{II})$.

\begin{tabular}{|lllllll|}
\hline \multirow{2}{*}{ Number } & $\mathrm{Cu}(\mathrm{II})$ & \multicolumn{5}{c|}{$\mathrm{Cd}(\mathrm{II})$} \\
\cline { 2 - 7 } & $\mathrm{q}_{\mathrm{m}}\left(\mathrm{mg} \cdot \mathrm{kg}^{-1}\right)$ & $\mathrm{b}\left(\mathrm{L}_{\mathrm{mgg}} \mathrm{m}^{-1}\right)$ & $\mathrm{R}^{2}$ & $\mathrm{q}_{\mathrm{m}}\left(\mathrm{mg} \cdot \mathrm{kg}^{-1}\right)$ & $\mathrm{b}\left(\mathrm{L} \cdot \mathrm{mg}^{-1}\right)$ & $\mathrm{R}^{2}$ \\
\hline 1 & 740.046 & 0.04694 & 0.992 & 416.635 & 0.01625 & 0.987 \\
5 & 582.691 & 0.00949 & 0.992 & 341.408 & 0.00292 & 0.975 \\
9 & 467.713 & 0.00401 & 0.983 & 244.191 & 0.00116 & 0.975 \\
\hline
\end{tabular}


kinetics of heavy metal removal from water by sludge-based activated carbon. J. China environmental science, 32(02): 254-259.

Duan, J.Q., Liu, Y.J. and Zhou, L. 2016. Preparation of activated carbon from sludge and its application in the treatment of blue carbon wastewater. J. Environ. Eng., 10(12) 6337-6342.

Lai, B., Zhou, Y.X. and Yang,P. 2012. Bioactive carbon treatment of ABS resin production wastewater. J. China Environ. Sci., 32(02): 254-259.

Li, G., Li, W.G. and Wang, G.Z. 2012. Preparation characterization and application of sludge-based activated carbon. J. Anhui Agric. Sci., 30(02): 489-493

Li, Y.L., Li-Ping, L.L., Weng-Jun, 1. and Li, J. 2013. Optimization and preparation of sludge-based activated carbon by two-step pyrolysis and performance. J. Beijing Univ. Technol., 39(12): 1887-1897.

Liu, H.P. and Liu, X.Z. 2013. The preparation of sludge-substrate activated charcoal and its property analysis. J. Fujian Univ. Technol., 33(01): $69-74$.
Li, Y.L., Liu, J.W., Chen, J.Y. and Shi, Y.F. 2014. Reuse of dewatered sewage sludge conditioned with skeleton builders as landfill cover material. J. Int J Environ Sci Technol, 11(1): 233-240.

Wang, R.F., Li, T. and Fan, L.Q. 2012. Bioactive carbon treatment of ABS resin production wastewater. J. Anhui Agric. Sci., 40(08): 4848-4849.

Wu, C.S., Huang, F.W., Liu, W.W., Liu, C.Q., Guo, Y.Y. and Zheng, Y.Y. 2017. Study on adsorption performance of sludge-based biochar to landfill leachate. J. Environ. Eng., 35(02): 1-4.

Yuan, L. and Liu, Y.Q. 2015. Catalytic effect of $\mathrm{MgSO}_{4}$ and $\mathrm{ZnCl}_{2}$ on the rapid pyrolysis of pine wood. J. Acta Energ. Sol. Sini., 36(07): 1775-1761.

Yang, H.Y. 2010. The present situation of municipal sewage and sludge treatment in China. J. North Environ. Mag., 22(01): 79-80.

Zheng, K.Q., Wang, J. C., Liu, S.T., Xue, H.B., Wu, J.Y., Liu, T.Y., Yi, W.Q. and Wang, X.Z. 2016. Adsorption characteristics of sludge Biochar for $\mathrm{Pb}^{2+}$ and $\mathrm{Cd}^{2+}$ at different pyrolysis temperatures. Chinese J. Environ. Eng., 10(12): 7277-7282. 